International Journal of Engineering \& Technology, $7(4.5)(2018) 707-712$
SPC
International Journal of Engineering \& Technology
Website $\frac{w w w . s c i e n c e p u b c o . c o m / i n d e x . p h p / I J E T}{2}$
Research paper

\title{
Glass fiber reinforced concrete (GFRC) - strength and stress strain behavior for different grades of concrete
}

\author{
Kiran Kumar Poloju ${ }^{1}$, Chiranjeeevi Rahul ${ }^{1}$, Vineetha Anil ${ }^{1}$ \\ ${ }^{1}$ Department of civil engineering, Middle East College, Muscat, Oman \\ *Corresponding author E-mail: kpoloju@mec.edu.om
}

\begin{abstract}
Concrete is a frail building material in strain. Characteristically, because of variety in temperature small cracks will be available in concrete. In addition, solid experiences low rigidity, constrained flexibility and little protection from splitting. Plain concrete will create splits because of plastic shrinkage, drying shrinkage and different reasons also. The advancement of these small scale breaks causes flexible miss happen-ing in concrete. The solid with no fiber is considered as fragile and feeble material. Related to glass fiber use there lies numerous techno efficient inquiries that settles on the decision of GFRC over strengthened cement troublesome. This paper exhibits the change in the mechan-ical quality properties and flexibility properties of Glass Fiber Reinforced Concrete. An Experimental program was done with and without utilizing glass fiber in various rate 0 to 0.09 percentages in conventional concrete keeping in mind the end goal to enhance the mechanical properties, stretch strain conduct and arrangement of splits. In light of the outcomes acquired from the trial comes about the conclusion is that both fiber and cementitious lattice can hold their physical and substance properties and they deliver a blend of properties that can't be accomplished when these segments are acting alone.
\end{abstract}

Keywords: Glass Fiber; Glass Fiber Reinforced Concrete; Compressive Strength; Stress- Strain Behavior; Ductility.

\section{Introduction}

Concrete is moderately good in compression yet frail in strain and has a tendency to be weak. The shortcoming in tension can be overwhelmed by the utilization of reinforcement and adequate quantity of fibers. The utilization of fibers additionally enhancing its durability and resists against cracks. Plain concrete is a fragile material, having the lesser values of young's modulus and strain limit. To meet the required value of flexural strength and upgrade the strain limit of the plain concrete, the fibers s are being utilized as a part of typical cement. The expansion of fibers in the plain concrete will control the splitting due to shrinkage and furthermore lessen the seepage of water. The expansion of glass fibers in plain concrete shows higher compressive strength than plain concrete. The fibers interlock and trap around aggregates and significantly decrease the workability, while the mix becomes more cohesive and less prone to segregation. The main considerations influencing the fiber strengthened concrete are: water proportion, volume of fibers used and dimensions of fibers. The location and extent of cracking under load will depend upon the orientation and numbers of fibers in cross section. The fibers improves the resistance towards shrinkage and creep movements of reinforced concrete. Fiber-reinforced concrete (FRC) can be grouped into two categories those with low modulus of elasticity and those with high modulus of elasticity. Synthetic, organic fibers, such as nylon, polypropylene and polyethylene, belong to the first category, whereas steel, glass, asbestos and carbon fibers belong to the second one. Use of the former group of fibers does not lead to increase in strength, but does improve material toughness and resistance to impact and explosive loadings. The latter group of fibers improves the strength and stiffness characteristics of concrete and, to a varying degree, its dynamic properties. Glass Fiber
Reinforced Concrete (GFRC) is a type of fiber reinforced concrete. Glass fiber reinforced concrete (GFRC) are the principal load-carrying members, while the surrounding matrix keeps them in the desired locations and orientation, acting as a load transfer medium between them, and protects them from environmental damage. In fact, the fibers provide reinforcement for the matrix and other useful functions in fiber-reinforced composite materials. Glass fibers can be incorporated into a matrix either in continuous lengths or in discontinuous (chopped) lengths. According to [1] GFRC provides an ideal system for achieving the durability requirements of new constructions. This research study investigated the characteristics of GFRC with varying percentage of addition to M20 grade of concrete. The objectives of the research work was to study the durability properties of M20 grade of concrete with varying percentages of addition of glass fibers $0.03 \%, 0.06 \%$ and $0.1 \%$ at $90,180,365$ and 720 days and compare with $0 \%$ at 90 , 180,365 and 720 days. The performance of GFRC increased with regard to durability. From the studies of [2] The percentage increase of compressive strength of various grades of glass fibre concrete mixes compared with 28 days compressive strength is observed from 20 to $25 \%$ and the percentage increase of flexural and split tensile strength of various grades of glass fibre concrete mixes compared with 28 days is observed from 15 to $20 \%$. [3] In this study, control mix A was designed as per IS 10262:1982 to achieve a target compressive strength of $20 \mathrm{Mpa}$. The glass fibers of $0 \%, 0.03 \%, 0.06 \%$ and $0.1 \%$ by volume fraction of concrete were used. In this experimental investigation cubes of $150 \mathrm{~mm} x$ $150 \mathrm{~mm} \times 150 \mathrm{~mm}$ of M-20 grade concrete were casted with varying percentage of addition of $0.03 \%, 0.06 \%$ and $0.1 \%$ of glass fiber. [5] The use of glass fibers has increased the compressive strength. Flexural strength using center point loading also meets the required parameters. In this study trial tests for concrete with $0.56 \%$ glass fiber and increasing\% hypo sludge are conducted to 
indicate the differences in compressive strength and flexural strength by using cubes \& beams. [7] Studies on investigating usage of paper industry waste in concrete was tested as an alternative to traditional concrete. The cement has been replaced by paper industry waste in different replacement levels like $0 \%, 10 \%$, $20 \%$, and $30 \%$ by weight for M-25 grade of concrete and found out strength properties. It was concluded that compressive strength was improved with $30 \%$ replacement of cement. Work has been conducted by [8] Based on experimental investigation on adding of Glass Fibre to plain concrete increases the strength and durability characteristics. Based on the test results it is noticed that strength characteristics like compressive, flexural and split tensile strength is gradually increased with the addition of glass fibres and concluded $1 \&$ is optimum. [9] In which they used steel fibres at $0.5 \%$ by volume of concrete and found out workability, compressive strength and split tensile strength and based on test results it was concluded that reduces workability of concrete in comparison to other fibers for different volume fraction and strength properties were increased. Also concrete reduces the cracks under different loading conditions and the brittleness of concrete can also be improved by addition steel fibers than glass fibers. Since concrete is very weak in tension, the steel fibers are beneficial in axial-tension to increase tensile strength. From the studies of [10] they casted cubes and cylinders with different proportions of glass fibres like $0.5 \%, 1 \%, 2 \%$ and $3 \%$ and tested for work ability, compressive strength, flexural strength, split tensile strength for M-20 grade of concrete at 7 and 28 days are observed from the results that addition of $1 \%$ can increase in strength properties and it is optimum. Also cement reduces the cracks under different loading conditions. It has been observed that the workability of concrete increases at $1 \%$ with the addition of glass fibre. Based on the experimental studies done by [11] on concrete mixes, they concluded that usage of alkali resistant glass fibers increases the strength properties without affecting workability of concrete. However compression strength with addition of fibres increase in strength up to $7 \%$ for M 20 grade and $8.8 \%$ for M 30 grade of concrete and split tensile strength for M $20 \&$ M 30 grade of concrete increased $24.7 \%$ and $26.10 \%$ respectively.

\section{Experimental procedure}

The Experimental program was intended to ponder the compressive strength and stress strain conduct of M20 grade $(6 \mathrm{~mm}$ length of glass fiber), M20 review (12mm length of glass fiber), M40grade (6mm length of glass fiber), M40 review (12 mm length of glass fiber) with and without expansion of glass fibers. The program comprised of casting and testing a specimen's number of ninety six examples. In this 48 specimens of cubes with measurements of $150 \mathrm{mmx} 150 \mathrm{mmx} 150 \mathrm{~mm}$ and 48 samples of prisms 100x100x $500 \mathrm{~mm}$. Of these 48 specimens of cubes 24 samples (different rates of glass fibers $0 \%, 0.03 \%, 0.06 \%$ and $0.09 \%$ ) are implied for M20 review of cement with $6 \mathrm{~mm}$ length of fibers utilized and 24 samples (different rates of glass fibers 0\%, 0.03\%, $0.06 \%$ and $0.09 \%$ ) implied for M20 review of cement with $12 \mathrm{~mm}$ length fibers utilized. Other 48 specimens of prisms 24 samples (different rates of glass fibers $0 \%, 0.03 \%, 0.06 \%$ and $0.09 \%$ ) are implied for M20 review of cement with $6 \mathrm{~mm}$ length of fibers utilized and 24 samples (different rates of glass fibers $0 \%, 0.03 \%$, $0.06 \%$ and $0.09 \%$ ) implied for M20 review of cement with $12 \mathrm{~mm}$ length fibers utilized.

\subsection{Materials used}

Cement: 53 Grade OPC used in the investigation. The cement was obtained from a single consignment with same grade \&same source. Few tests were done on cement like specific gravity, normal consistency and both initial \& setting time and it was noticed from the test results are $3.15,32 \%, 34$ min \& 210 min respectively
Fine Aggregate: Zone 2 aggregate was used in this investigation. The bulk density, specific gravity, and fineness modulus of the sand used were $1.41 \mathrm{~g} / \mathrm{cc}, 2.68$, and 2.90 .

Coarse Aggregate: The coarse aggregate was obtained from a local crushing unit having $20 \mathrm{~mm}$ well graded aggregate is used in this investigation. The bulk density, specific gravity and fineness modulus of the coarse aggregate used were $1.46 \mathrm{~g} / \mathrm{cc}, 2.78$ and 7.1 . Water: Potable water was used in the experimental work for both mixing and curing

Glass fibers: Some of the typical properties of Glass

Table 1: Properties of Glass Fibers

\begin{tabular}{lll}
\hline $\begin{array}{l}\text { S. } \\
\text { No }\end{array}$ & Trade name & $\begin{array}{l}\text { Cem-FIL anti-crack high dispersion } \\
\text { glass fibers }\end{array}$ \\
\hline 1 & Number of fibers & $212 \mathrm{million} / \mathrm{kg}$ \\
& $\begin{array}{l}\text { Aspect ratio for } 6 \mathrm{~mm} \text { and } \\
2\end{array}$ & $\begin{array}{l}\text { 12mm } \\
\text { respectively }\end{array}$ \\
& $428.57,857.1$ \\
3 & Specific surface area & $105 \mathrm{~m} 2 / \mathrm{kg}$ \\
4 & Typical addition rate & 0.6 to $1.0 \mathrm{~kg} / \mathrm{m} 3$ of concrete \\
5 & Tensile strength & $1700 \mathrm{Mpa}$ \\
6 & Modulus of elasticity & $73 \mathrm{GPa}$ \\
7 & Corrosion resistance & Excellent \\
8 & Specific gravity & 2.6 \\
9 & Density & $26 \mathrm{kN} / \mathrm{m} 3$ \\
10 & Filament diameter & $14 \mu$ \\
11 & Filament length & $6 \mathrm{~mm}$ and $12 \mathrm{~mm}$ \\
\hline
\end{tabular}

Aggregate Properties: The specific gravity of coarse aggregate was determined as per IS 2386. The specific gravity of natural aggregate is presented in Table 2 . The average specific gravity of aggregate usually varies from 2.6 to 2.8

Table 2: Properties of Natural Aggregate

\begin{tabular}{ll}
\hline Properties & Natural Aggregate \\
\hline Bulk Density & 1.46 \\
$\%$ of Voids & 44.26 \\
Void Ratio & 0.79 \\
Specific Gravity & 2.78 \\
Fineness Modulus & 7.1 \\
\hline
\end{tabular}

\subsection{Mix design proportions}

Two different grades M20, and M40 mix were designed and Glass fiber of different lengths were added $0 \%, 0.03 \%, 0.06 \%$, and $0.09 \%$ of volume of concrete. The proportions arrived for different grades of concrete are given in the Table 3 .

Table 3: Mix Proportions for M20 and M40 Grade of Concrete with and Without Glass Fibers

\begin{tabular}{|c|c|c|c|c|c|c|c|}
\hline & $\begin{array}{c}\text { Length of } \\
\text { Mix glass fiber } \\
(\mathrm{mm})\end{array}$ & $\begin{array}{l}\text { C.A/ } \\
\text { F.A }\end{array}$ & $\begin{array}{l}\text { Coarse } \\
\text { aggregate } \\
\mathrm{Kg} / \mathrm{m} 3\end{array}$ & $\begin{array}{l}\text { Fine aggre- } \\
\text { gate } \mathrm{Kg} / \mathrm{m} 3\end{array}$ & $\begin{array}{l}\text { Cement } \\
\mathrm{Kg} / \mathrm{m} 3\end{array}$ & $\begin{array}{l}\text { Water } \\
\mathrm{Kg} / \mathrm{m} 3\end{array}$ & $\begin{array}{l}\text { W/C } \\
\text { Ratio }\end{array}$ \\
\hline & M206 & $40 / 60$ & 1292 & 559 & 383 & 191.6 & 0.50 \\
\hline & M2012 & $40 / 60$ & 1292 & 559 & 383 & 191.6 & 0.50 \\
\hline & M406 & $40 / 60$ & 1387 & 438 & 450 & 135 & 0.3 \\
\hline & M4012 & $40 / 60$ & 1387 & 438 & 450 & 135 & 0.3 \\
\hline
\end{tabular}

\section{Results}

The trial examinations are directed so as to contemplate the compressive strength and stress-strain conduct of different parameters on M20 and M40 grades with and without glass fiber and the test outcomes are discussed here. 


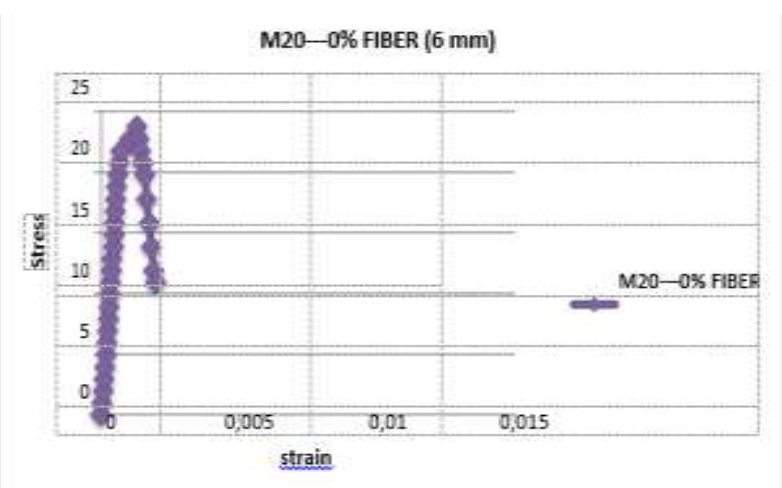

Fig. 1: Stress vs. Strain for M20 Grade of Concrete with $0 \%(6 \mathrm{~mm})$ Fiber Content Respectively.

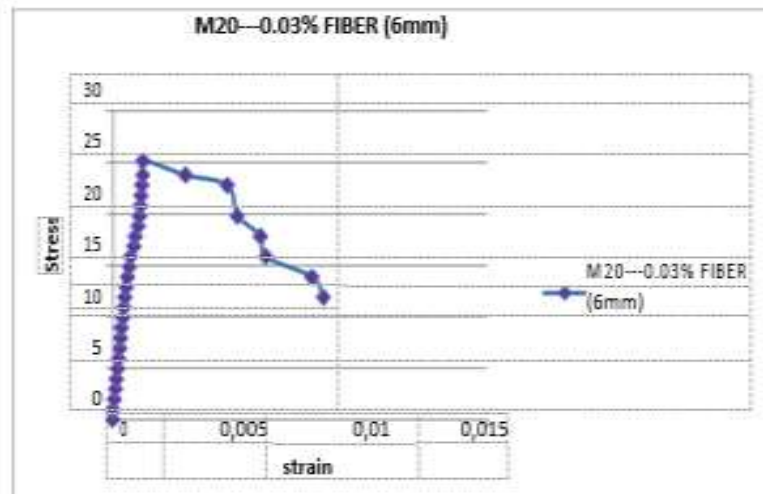

Fig. 2: Stress vs. Strain for M20 Grade of Concrete with $0.03 \%(6 \mathrm{~mm})$ Fiber Content Respectively.

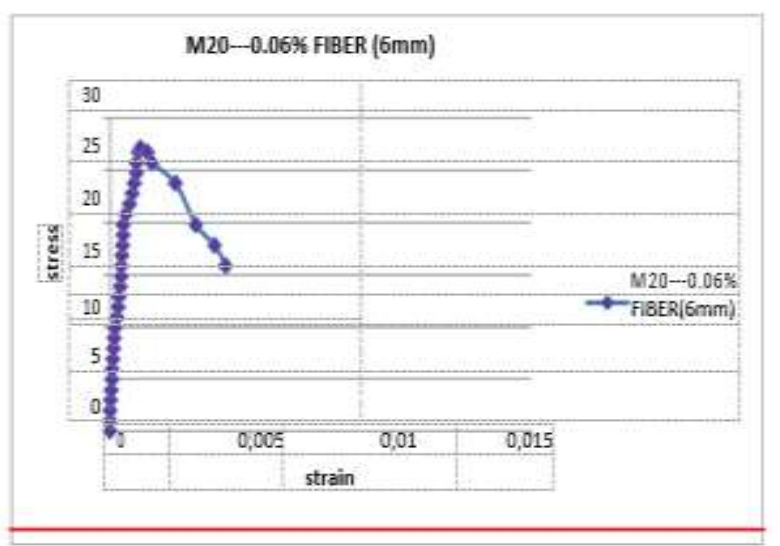

Fig. 3: Stress vs. Strain for M20 Grade of Concrete with $0.06 \%$ (6mm) Fiber Content Respectively.

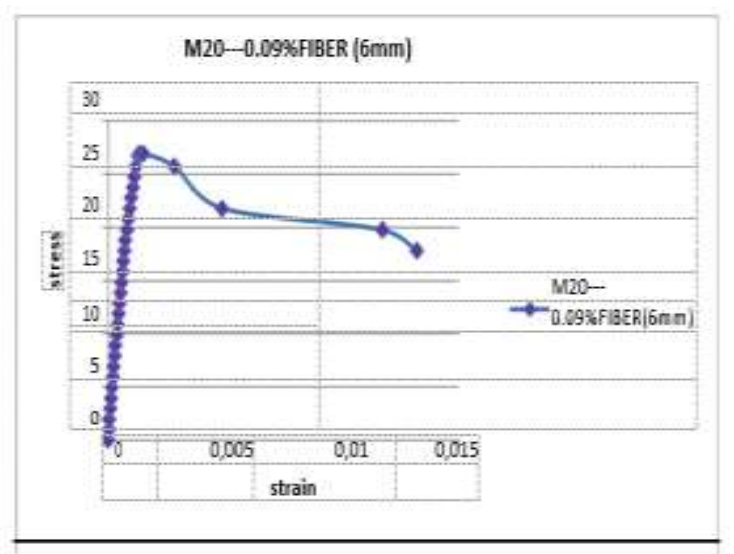

Fig. 4: Stress vs. Strain for M20 Grade of Concrete with $0.09 \%$ (6mm) Fiber Content Respectively.

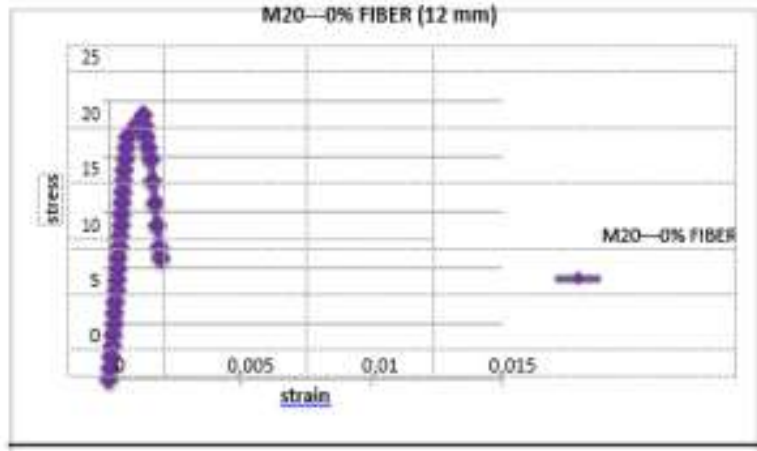

Fig. 5: Stress vs. Strain for M20 Grade of Concrete with $0 \%$ (12mm) Fiber Content Respectively.

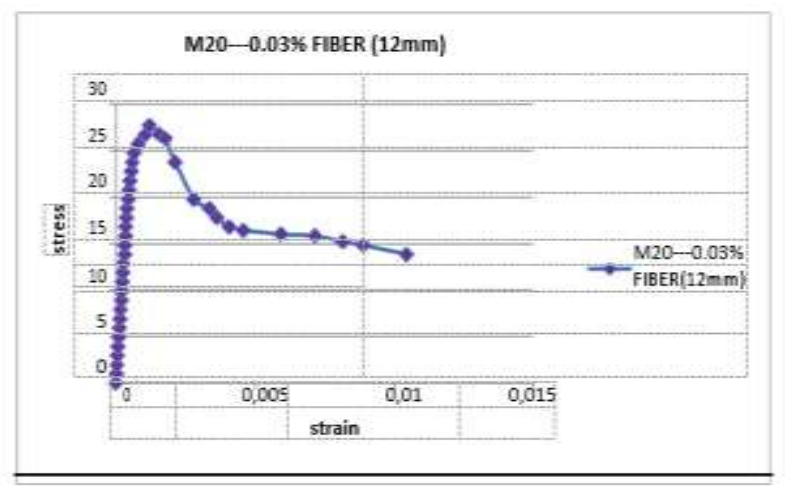

Fig. 6: Stress vs. Strain for M20 Grade of Concrete with $0.03 \%(12 \mathrm{~mm})$ Fiber Content Respectively.

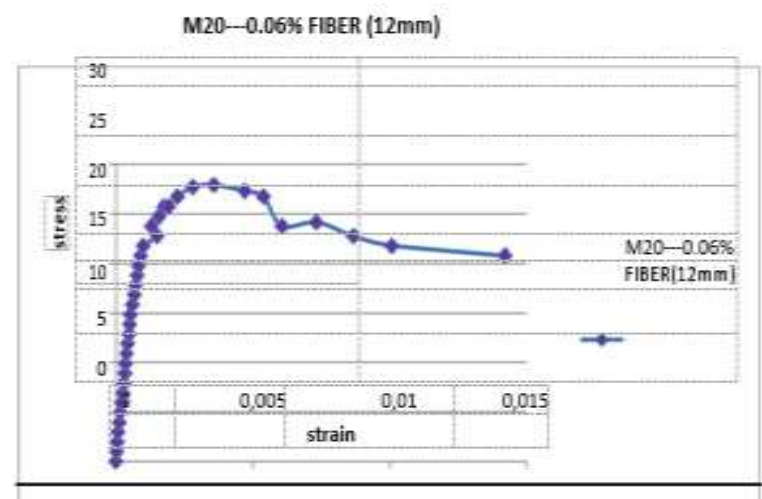

Fig. 7: Stress vs. Strain for M20 Grade of Concrete with $0.06 \%(12 \mathrm{~mm})$ Fiber Content Respectively

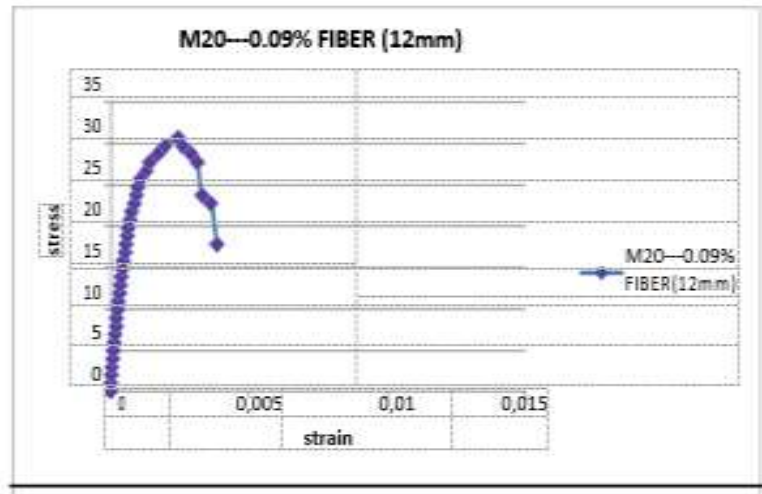

Fig. 8: Stress vs. Strain for M20 Grade of Concrete with $0.09 \%(12 \mathrm{~mm})$ Fiber Content Respectively. 


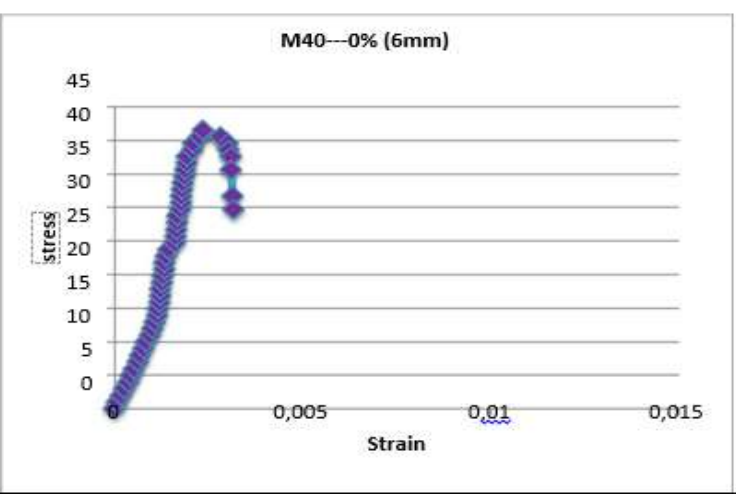

Fig. 9: Stress vs. Strain for M40 Grade of Concrete with $0 \%(6 \mathrm{~mm})$ Fiber Content Respectively.

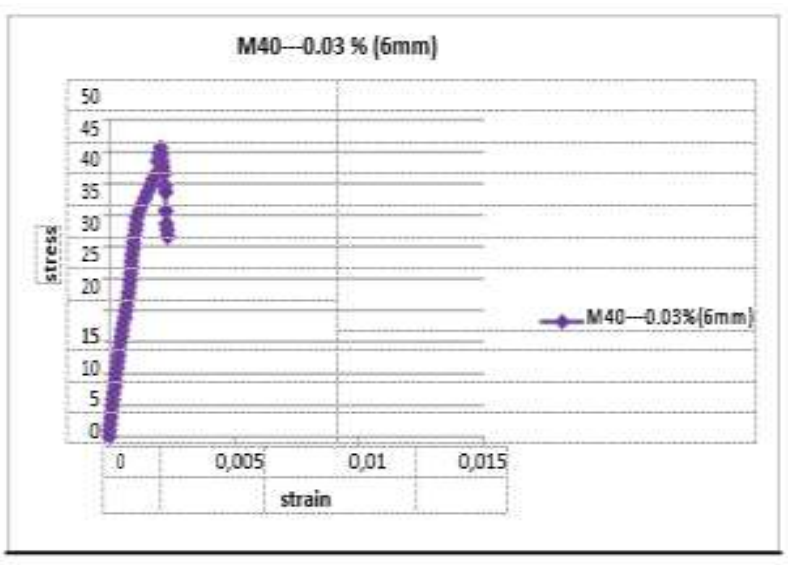

Fig. 10: Stress vs. Strain for M40 Grade of Concrete with $0.03 \%(6 \mathrm{~mm})$ Fiber Content Respectively.

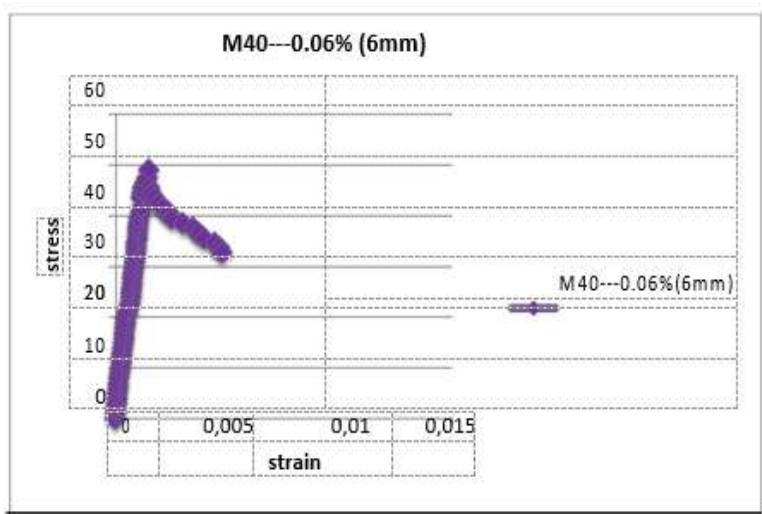

Fig. 11: Stress vs. Strain for M40 Grade of Concrete with $0.06 \%(6 \mathrm{~mm})$ Fiber Content Respectively.

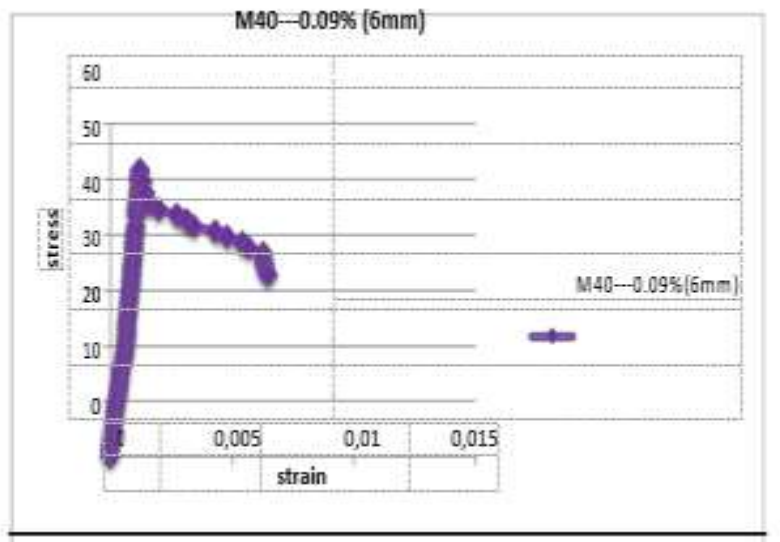

Fig. 12: Stress vs. Strain for M40 Grade of Concrete with $0.09 \%$ (6mm) Fiber Content Respectively.

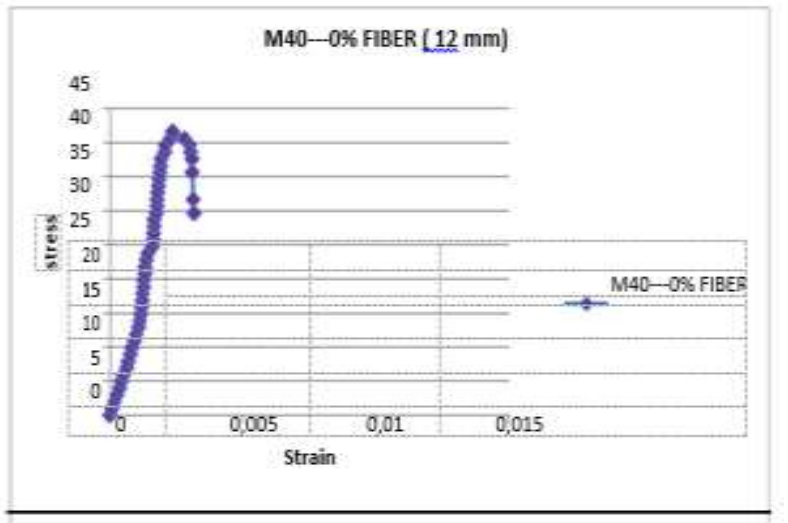

Fig. 13: Stress vs. Strain for M40 Grade of Concrete with $0 \%(12 \mathrm{~mm})$ Fiber Content Respectively.

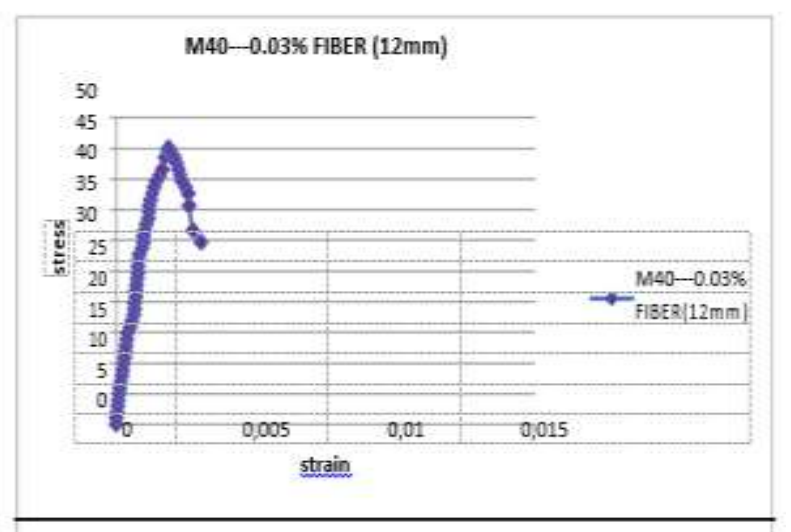

Fig. 14: Stress vs. Strain for M40 Grade of Concrete with $0.03 \%(12 \mathrm{~mm})$ Fiber Content Respectively.

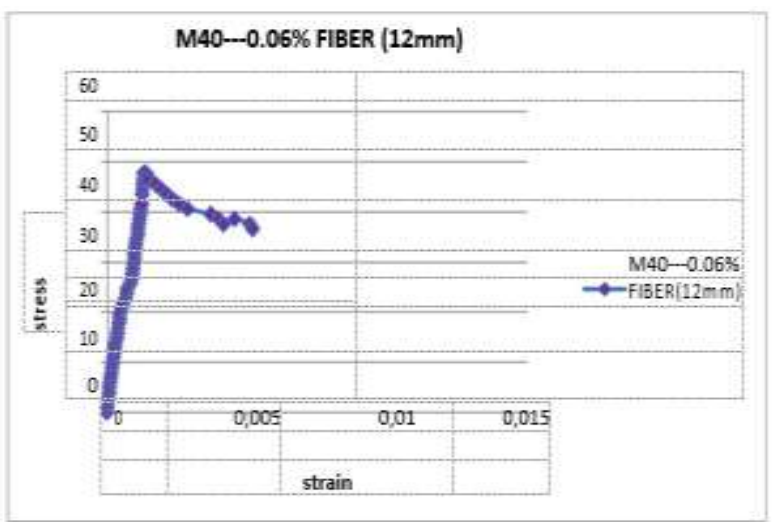

Fig. 15: Stress vs. Strain for M40 Grade of Concrete with $0.06 \%(12 \mathrm{~mm})$ Fiber Content Respectively.

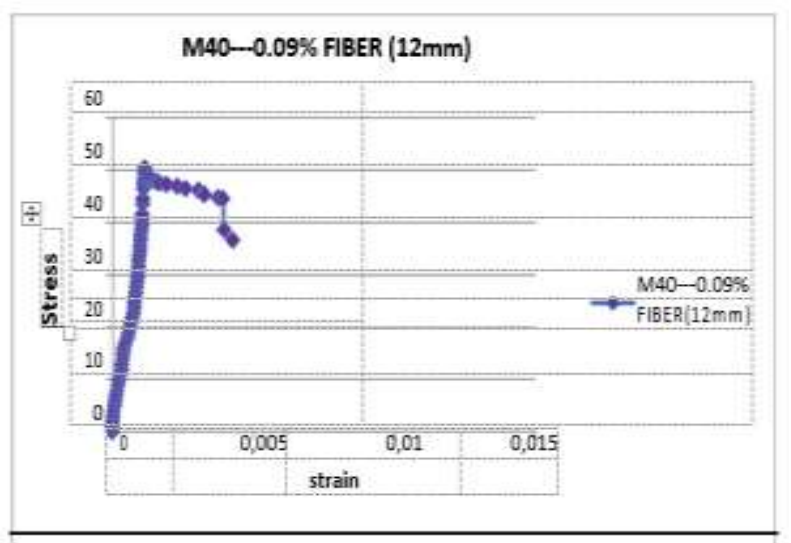

Fig. 16: Stress vs. Strain for M40 Grade of Concrete with $0.09 \%(12 \mathrm{~mm})$ Fiber Content Respectively. 


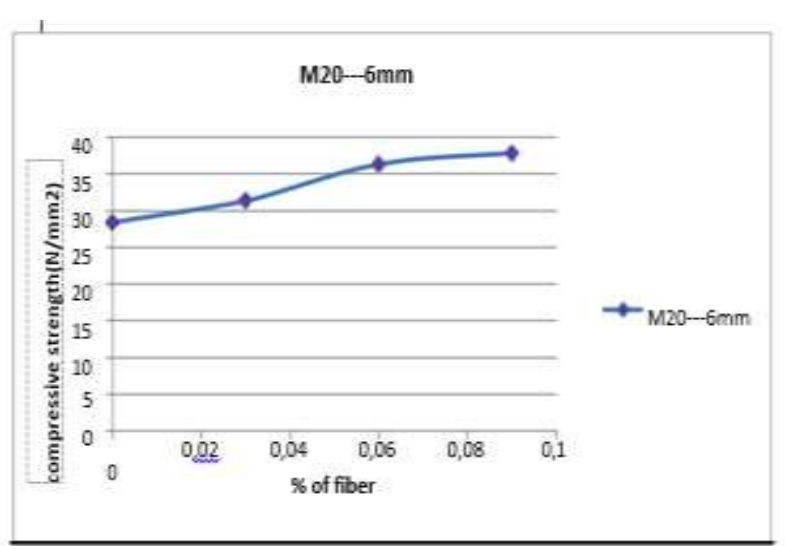

Fig. 17: Compressive Strength vs. \% of Glass Fiber (6 Mm) M20 Grade Respectively.

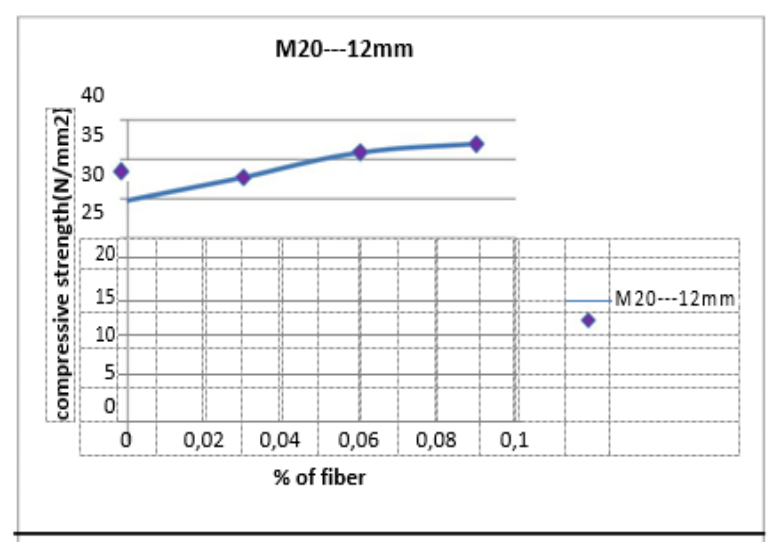

Fig. 18: Compressive Strength vs. \% of Glass Fiber (12 Mm) M20 Grade Respectively.

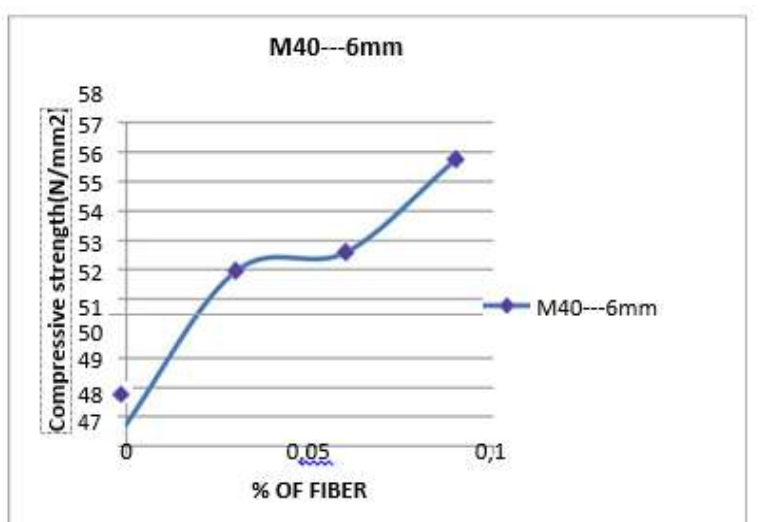

Fig. 19: Compressive Strength vs. \% of Glass Fiber (6 Mm) M40 Grade Respectively.

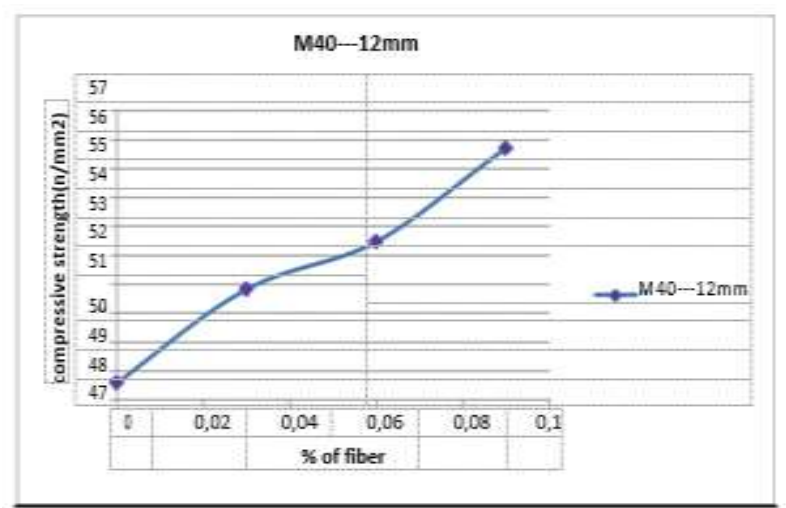

Fig. 20: Compressive Strength vs. \% of Glass Fiber (12 Mm) M40 Grade Respectively.

\section{Discussion}

Effect of Glass Fiber on strain at ultimate: From Fig. 1 to Fig. 16, fibers used are different lengths i.e. $6 \mathrm{~mm}$ and $12 \mathrm{~mm}$, from the graphs it was observed that, $12 \mathrm{~mm}$ fibers improve strength and strain capacity compared with $6 \mathrm{~mm}$. GFRC specimens have shown improved deformation capacity after reaching ultimate load. As the percentage of fiber increased, deformation, i.e. strain at breaking has increased.

Compressive strength - From Fig. 17 to Fig. 20 indicates that with the addition of glass fiber, the pre-peak loading portion of the load-deflection curve changes very slightly, but the post peak loading portion of the load-deflection curve becomes less steep, which resulted in a higher ductility of the material. Also as the \% of fiber increases, the compressive strength increases. It indicates that with the addition of glass fiber in the outer shell of the cubes the compressive strength is gradually increased with increased \% of fiber, but better strength results compared to $12 \mathrm{~mm}$ fibers.

\section{Conclusion}

This investigation comprise of testing specimens and shapes comprehend the improvement of compressive strength, stress strain quality of concrete with various rates of fibers.

1) Compressive strength of concrete is expanded with the expansion in level of glass fibres

2) Of the three fiber substance, i.e., $0.03 \%, 0.06 \%$ and $0.09 \%$, Example with $0.09 \%$ gave higher increment in strength than the other two.

3) It is noticed that change in strength and strain of GFRC example past extreme quality expanded with increase in fiber.

4) Strength of GFRC specimen with fibers used in outer shell and used in complete specimen has shown that, the strength of specimen is same as in both types. This may be due to the fact that the fibers in outer shell have contributed to confinement; also confinement effect can be realized only after reaching ultimate strength. Hence it can be concluded that fibers may be used only in outer shell.

5) GFRC specimens have demonstrated enhanced disfigurement limit subsequent to achieving extreme load. As the level of fiber expanded, mishapening, i.e. endure breaking has expanded.

6) Ductility of concrete specimens expanded by giving GFRC external shell.

\section{References}

[1] Chandramouli K., Srinivasa Rao P., Seshadri Sekhar T., Pannirselvam N. and Sravana P (March 2010) "VOL. 5, NO. 3, ARPN Journal of Engineering and Applied Sciences pp: $67-71$.

[2] Chandramouli K, Srinivasa Rao P, "Strength properties of glass fiber concrete", ARPN Journal of Engineering and Applied Sciences, VOL. 5, NO. 4, APRIL 2010.

[3] Deshmukh S.H., Bhusari J. P, Zende A. M "Effect of Glass Fi-bers on Ordinary Portland cement Concrete, IOSR Journal of Engineering June. 2012, Vol. 2(6) pp: 1308-1312.

[4] Rapid chloride permeability test for durability studies on glass fiber reinforced concrete, ARPN Journal of Engineering and Applied Sciences, VOL. 5, NO. 3, MARCH 2010.

[5] Jayeshkumar Pitroda, Dr. L. B. Zala, Dr F. S Hypo Sludge Management: Opportunities for Developing Low Cost Concrete with Glass Fibers. Umrigar: volume 1, Issue: 7, Dec 2012, ISSN No $2277-8160$

[6] IS 10262 (1982), Recommended guidelines for Concrete Mix Design, Bureau of Indian Standards, New Delhi.

[7] Kiran Kumar Poloju, Ram Kishore Manchiryal, Chiranjeevi Ra-hul R (2017). Development of sustainable concrete by using paper Industry waste, Elixir Civil Engg. 102 (2017) 44152-44154 44152

[8] S.Hemalatha, Dr.A.Leema Rose. AN EXPERIMENTAL STUDY ON GLASS FIBRE REINFORCED CONCRETE in International Research Journal of Engineering and Technology (IRJET) e-ISSN: 2395 -0056 Volume: 03 Issue: 04 | April-2016 .Page 2285. 
[9] Kavita S Kene, Vikrant S Vairagade and Satish Sathawane. Experimental Study on Behavior of Steel and Glass Fiber Reinforced Concrete Composites in Bonfring International Journal of Industrial Engineering and Management Science, Vol. 2, No. 4, December 2012125.

[10] J. D. Chaitanya kumar, G.V.S. Abhilash, P.Khasim Khan, G. Manikanta sai, V. Taraka ram. Experimental Studies on Glass Fiber Concrete in American Journal of Engineering Research (AJER) eISSN: 2320-0847 p-ISSN: 2320-0936 Volume-5, Issue-5, pp-100104.

[11] Md. Abid Alam, Imran Ahmad and Fazlur Rehman. Experi-mental Study on Properties of Glass Fibre Reinforced Concrete in International Journal of Engineering Trends and Technology (IJETT) Volume 24 Number 6- June 2015 ISSN: 2231-5381 http://www.ijettjournal.org Page 297. 